\title{
The effects of overtraining and delay on reversal and nonreversal shifts in kindergarten children
}

\author{
WAYNE VINEY, COLORADO STATE UNIVERSITY \\ GLENA ADEN VARNER, OKLAHOMA CITY UNIVERSITY
}

Kindergarten children were randomly assigned to one of eight treatment conditions in a 2 by 2 by 2 factorial design involving reversal and nonreversal shifts, criterion and overtraining, and immediate and delayed shifts. The problems were composed of a two-choice discrimination involving shape or brightness. A reversal shift consisted of shifting from the positive to the negative cue within a dimension, and a nonreversal shift consisted of shifting to a different dimension. The only significant finding was that the 24-h delay between training and transfer trials improved performance in the other conditions. Possible explanations for these findings were offered.

Stevenson \& Weir (1959) demonstrated that delay but not overtraining facilitates the speed with which 6 to 8-year-old children learn reversal responses on a three-choice spatial discrimination problem. Youniss \& Furth (1964), however, demonstrated that both delay and overtraining improve the speed with which 7 and 8-year-old children learn the reversal of a three-choice paired associate task. In subsequent investigations of the overlearning reversal effect (ORE) upon the performance of children, both positive (Youniss \& Furth, 1965; Cross \& Tyer, 1966) and negative (Viney, 1964; Vaughter \& Cross, 1965) results have been reported. In light of these conflicting results, the present study was undertaken to further explore the effects of both overtraining and delay upon reversal and nonreversal type problems. Simple two-choice discrimination problems were utilized because such problems seemed appropriate to the age level of Ss used in this experiment.

Subjects

The Ss were 64 kindergarten children from two lowerclass elementary schools in Oklahoma City, Oklahoma. The mean age was five years. Ten males and 12 females were eliminated for failure to learn the original discrimination after 90 trials. $^{1}$ These Ss were replaced. Apparatus

The apparatus (for detalls, see Viney, 1964) was a turntable device with two depressions which could contain marble rewards and an opaque board which screened the movements of $E$ from S. Discriminanda which were used to cover the depressions consisted of four enameled geometric shapes. One pair contained two rectanglesone black and one white-measuring $2 \times 4-1 / 2$ in. The other pair consisted of a mid-gray circle and square each having an area of 9 in.

Procedure

The Ss were tested individually in a quiet room in which $\mathbf{E}$ and $\mathrm{S}$ were alone. The $\mathrm{E}$ greeted each $\mathrm{S}$ and attempted through informal conversation to create some rapport with him. The $E$ then explained the game they would play and indicated the inexpensive toys which would serve as prizes. $S$ was given the following instructions:

"We are going to play a game. The name of the game is 'Find the Hidden Marble.' Look at the two holes in this side of the table. I have some marbles, and I will put one of them in one of these holes. Then I will cover both holes with these objects (here $\mathrm{E}$ indicates the discriminanda). You try to guess which object covers a marble and pick it up. If it is there, place the marble in this dish (here $\mathrm{E}$ indicates a white plastic container provided for S's marbles). If it is not there, I will turn the table around and we will try again. Remember that you may choose only one object each time and that your job is to find the marble every time. At the end of the game, you will be able to trade your marbles in for one of the prizes that you see here."

When $\mathrm{E}$ was certain $\mathrm{S}$ understood the directions, the test was begun. No further instructions were given except the reminder to try to get the marble every time. Following the placing of the marble and the discriminanda, the turntable was rotated $180^{\circ}$ to face S while $E$ was located directly behind the screen. The marble was placed on the right or left on a random basis and covered with the positive discriminandum. In order to avoid run effects, a control was used so that if an object appeared in one position for three successive trials, it was automatically changed on the next trial.

Each $S$ was assigned to one of eight treatments in a 2 by 2 by 2 factorial design involving the following: criterion vs overtraining; immediate vs delayed shift; and reversal vs nonreversal shift. When S achieved nine successive correct choices he was considered to have learned the task. Criterional learning was followed by $100 \%$ overtraining for half the Ss. Overtraining was based on the total number of acquisition trials including the final nine trials. Thus, if a S's total number of trials in acquisition, including the final nine, was 18 , he was given an additional 18 trials. When each $S$ reached the condition of training to which he had been assigned, he was shifted to the critical task. Half of the Ss were shifted immediately and half had a 24-h delay before the shift. Reversal shift problems involved a shift in the second task from the formerly positive to the formerly negative object. Thus, if a $\mathrm{S}$ was originally confronted with circle positive and square negative, he was shifted to square positive and circle negative. Nonreversal 
Table 1

Means and standard deviations of number of trials to

criterion in all experimental conditions

\begin{tabular}{lccccccccc}
\hline & \multicolumn{4}{c}{ Reversal Shift } & \multicolumn{3}{c}{ Nonreversal Shift } \\
& Criterion & \multicolumn{3}{c}{ Overtraining } & \multicolumn{3}{c}{ Criterion } & \multicolumn{2}{c}{ Overtraining } \\
& I & D & I & D & I & D & I & D \\
\hline Mean & 15.75 & 4.38 & 8.12 & 2.38 & 8.38 & 6.50 & 13.50 & 3.50 \\
S.D. & 4.16 & 5.52 & 5.28 & 2.40 & 12.79 & 11.63 & 18.98 & 5.92 \\
\hline
\end{tabular}

shift problems consisted simply of introduction of a new dimension after original learning. Thus if the circlesquare (shape) combination was originally present, then the transfer task involved learning a black-white (brightness) discrimination. All possible permutations of the discriminanda were used for both reversal and nonreversal conditions. Each $\mathrm{S}$ was confronted with only one of the possible shifts.

\section{Resulfs and Discussion}

Pretransfer equivalence was indicated by an analysis of variance which indicated no significant differences between any of the main effects or interactions of the initial learning data.

The original shift data, consisting of trials to criterion, were heterogeneously variable $(F \max =62.81, \mathrm{df}=$ $8 / 7, p<.01$ ) so a $\sqrt{\mathrm{x}+5}$ transformation was performed in order to proceed with the analysis. This transformation sufficiently reduced heterogeneity $(F \max =10.18$, df $=$ $8 / 7, p>.05)$ to warrant use of the analysis of variance. The means and standard deviations of the original (untransformed) scores are presented in Table 1 .

Analysis of variance based on the transformation of the data in Table 1 indicated a significant $(F=8.34$, df $=1 / 56, p<.01$ ) delay effect. The shift effect, training effect, and interactions did not approach significance. The delay effect is supportive of the Stevenson \& Weir (1959) study which found reversal improvement following delay but not overtraining. The delay condition perhaps permits some forgetting, reduces perseverative errors, and facilitates perception of a change in the learning conditions. The failure of the overtraining condition in this and other studies is more difficult to explain. Explanation is especially difficult in view of the fact that other studies (e.g., Viney, 1964; Wattenbarger \& Viney, 1965) along with the present study show nonsignificant results, but the direction of these results, nevertheless, consistently favors overtrained groups.
This suggests that overtraining may have an effect upon human discrimination performance, but the effect is apparently as subtle and difficult to reproduce with children as it is with animals (D'Amato \& Jagoda, 1961). One tenable explanation of the problem is offered by Cross \& Tyer (1966), who have suggested that ontogenetic level and perceptual experience are crucial factors in determining the presence of ORE. These investigators accordingly demonstrated the presence of ORE in younger but not in older nursery children. If this explanation is correct, one might expect to find significant ORE effects with kindergarten children or older children by increasing the complexity of the discrimination task.

Failure to find a significant shift effect may indicate that reversal problems are not more difficult than nonreversal problems when preceded by conditions of overtraining and/or delay. The only time that reversal problems appeared more difficult was when reversal was immediate and preceded by criterional training conditions.

\section{References}

Cross, H. A., \& Tyer, Zita E. The overlearning reversal effect in preschool children as a function of age. Psychon. Sci., 1966 , 6, $175-176$.

D'Amato, M. R., \& Jagoda, H. Analysis of the role of overlearning in discrimination reversal. $J$. exp. Psychol., 1961, 61, 45-50.

Stevenson, H. W., \& Weir, M. W. Response shift as a function of overtraining and delay. J. comp. physiol. Psychol., 1959, 52, 327-329.

Vaughter, R. M., \& Cross, H. A. Discrimination reversal performance in children as a function of prereversal experience and overlearning. Psychon. Sci., 1965, 2, 363-364.

Viney, A. W. The effects of overtraining on reversal and nonreversal shifts in fast and slow learners. Unpublished doctoral dissertation, University of Oklahoma, 1964.

Wattenbarger, B., \& Viney, A. W. The effects of overtraining on reversal and nonreversal shifts in nursery school children. Paper delivered at Southwestern Psychol. Assoc., Oklahoma City, April 8, 1965.

Youniss, J., \& Furth, H. G. Reversal learning in children as a function of overtraining and delayed transfer. J. comp. physiol. Psychol., 1964, 57, 155-157.

Youniss, J., \& Furth, H. G. Discrimination shifts as a function of degree of training in children. J. exp. Psychol, 1965, 70, 414-427. Note

1. Failure of some Ss to learn the original task may be a function of both social class factors and the criterion used. Similar reports of other researchers, of failure of some Ss to learn the original task, indicates a need for closer investigation of conditions which are related to such failures. 